\title{
EFFECT OF SIMVASTATIN AND ANTIOXIDANT MIX ON PULPOTOMIZED YOUNG PERMANENT TEETH: A CLINICAL AND RADIOGRAPHIC STUDY
}

\author{
Mohamed A. Abd Elmegeid Mohamed *, Samy Yousef Elbayomy ${ }^{* *}$, Abd Elhamed Abou El Yazed Eisa ${ }^{* * *}$
}

\begin{abstract}
Objective: The objective of this study was to evaluate, clinically and radiographically, the effect of Simvastatin and Antioxidant mix on pulpotomized young permanent teeth. Subjects \& Methods: Pulpotomy was performed in 54 vital decayed young permanent molars that were indicated for vital pulp therapy. The molars were classified randomly into three equal groups: Group A: molars receiving Simvastatin after pulpotomy $(n=18)$; Group B: molars receiving Antioxidant mix after pulpotomy $(n=18)$; Group C: molars were receiving calcium hydroxide after pulpotomy $(n=18)$. The treated teeth were followed up clinically and radiographically after variable intervals (immediately, 1 month and 3 months) after treatment. The assessment of treated teeth was performed by visual inspection of the signs and symptoms and by periapical radiographs for assessment of pulp space, lamina dura and periapical tissue. Result: According to pain, mobility, swelling, internal or external resorption, widening of periodontal ligament and periapical radiolucency; in simvastatin group at 3 months, 15 (83.3\%) of cases were successful and 3 cases failed. Antioxidant mix, at 3 months, $16(88.9 \%)$ of cases were successful and 2 cases was failed. Calcium hydroxide, at 3 months, 16 $(88.9 \%)$ of cases were successful and 2 cases failed. Conclusion: Simvastatin and Antioxidant mix pulpotomy are more costeffective, handled easilily, and biocompatible. It has been proven potentially to be an ideal pulpotomy agent in the treatment of vital young permanent teeth. All three tested materials enhancing root formation "elongation" without significant difference, without any change in periodontal tissue.
\end{abstract}

KEYWORDS: Simvastatin, Antioxidant mix, calcium hydroxide.

\section{INTRODUCTION}

Dental caries is one of the most common chronic diseases affecting millions of people. Caries activity usually causes tooth decay or cavities and can even lead to the loss of afflicted teeth, which is particularly harmful to children's growth and development ${ }^{(1)}$. The World Health Organization (WHO) reported that $60-90 \%$ of school children experience caries globally. Preservation of the remaining vital portion of cariously exposed pulpal tissue in primary teeth, where the demand is to keep a functioning tooth in site, was one of the most frequent problems in pediatric dentistry ${ }^{(2)}$.

Vital pulp therapy is the treatment of choice for pulp exposures in immature teeth with irreversible pulpits and/or traumatic injuries. The procedure is primarily based on the healing ability of the healthy pulp. Two well-established methods for pulp preservation are direct pulp capping and pulpotomy ${ }^{(3)}$. Pulpotomy is a common procedure in the treatment of inflamed primary teeth and management of young permanent teeth with open

\footnotetext{
* Masters Candidate, Ministry of Health.

** Professor of Pedodontics and Oral Health. Faculty of Dental Medicine, Boys, Cairo. AlAzhar University.

*** Lecturer of Pedodontics and Oral Health Faculty of Dental Medicine, Boys, CairoAl-Azhar University .
}

-Coressponding author: mohamedgedostar@yahoo.com

DOI: 10.21608 /ajdsm.2020.25745.1031 
apices, consists of the surgical amputation of coronal inflamed pulp and treatment of the wounded surface of the radicular pulp is treated with a medicament or dressing agent to promote healing or to fix of the underlying tissue ${ }^{(4)}$.

Pulpotomy dressings have been examined more recently such as formocresol, calcium hydroxide, freeze-dried bone, gluteraldehyde, ferric sulfate, bone morphogenic protein, mineral trioxide aggregate (MTA) ${ }^{(5)}$.

Statins are structural analogs of HMG-CoA (3-hydroxy-3-methylglutaryl-coenzyme A). These drugs are the first line for hyperlipidemia, and it have been recognized to be a safe and low-priced drug as a result of its worldwide longtime usage ${ }^{(6)}$. Moreover, statin has multiple functions including induction of angiogenesis, anti-inflammation and improvement of the vascular endothelial cell function. Another interesting and important function of statin is its effect on bone formation ${ }^{(7)}$.

It has been reported that several statins such as simvastatin and lovastatin have anabolic effects on bone metabolism at in vitro and in vivo study. They promote mineralization in non-mineralizing osteoblasts through induction of BMP-2 and osteocalcin ${ }^{(8)}$. Furthermore; in vitro study showed that statins promote osteoblastic differentiation in mouse osteoblastic cells ${ }^{(9)}$.

Antioxidant mix is a newer pulpotomy medicament which works on the principle of wound healing and maintains anatomically continuity of damaged tissue ${ }^{(10)}$. Healing involves the activity of an intricate network of blood cell, growth factors, and cytokines which ultimately leads to the restoration to a normal condition of the injured radicular tissue. Antioxidants encounter excess of proteases and free radicals which are often formed by neutrophils accumulation in the wounded area and protect protease inhibitors from oxidative damage ${ }^{(11)}$.

Antioxidant mix has major advantages that are biocompatibility and various other unique features that overcome the disadvantages of another medicament. Antioxidant mix seems to be a newer choice of medicament for pulpotomy ${ }^{(12)}$. Although both simvastatin and antioxidant mix are used as pulpotomy material for primary teeth, however, little clinical information is available regarding the use of both material on permanent teeth ${ }^{(10,13)}$.

\section{SUBJECTS, MATERIALS AND METHODS}

The study was carried out on 54 vital decayed young permanent molars that indicated for vital pulp therapy. The children were selected from Pedodontics outpatient's clinic, Faculty of Dental Medicine, Boys, Cairo, and Al-Azhar University. The present study comprised three main groups. Pulpotomy procedure was performed in children, ranging from 6-9 years. The children and their parents were informed about the purpose of the study and an informed consent document prior to participation was signed.

\section{Inclusion criteria:}

Patients should have, at least one, a deeply carious vital first permanent molar with incompletely root formed. These young permanent molars were selected according to the following criteria:

1. The molars should be vital on testing with vitality tests.

2. The molars should have deep carious lesions.

3. The periapical area should be clear of any inflammation or pathosis.

4. The age of the patients should range from 6-9 years.

\section{Exclusion criteria:}

1. History of spontaneous, unprovoked toothache.

2. Mobility.

3. Sensitivity for percussion.

4. Presence of fistulae.

5. Peripheral or internal root resorption.

6. Carious furcation involvement.

7. Periapical lesions.

8. Dystrophic calcification of the pulp. 


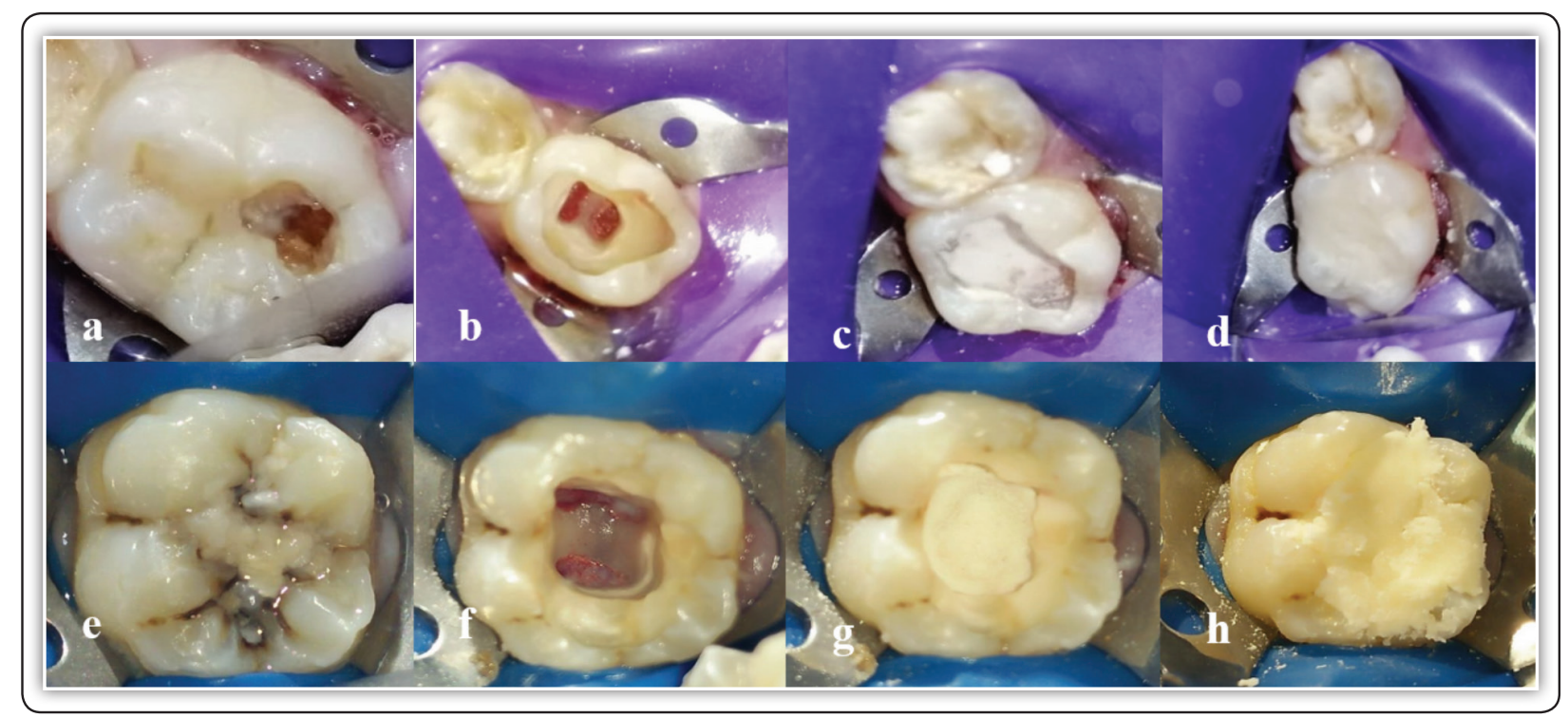

FIG (1) Simvastatin group: a: pre-treatment lower left first permanent Molar; b: Gaining access and cavity preparation; c: placement of simvastatin paste, d; Glass Ionomer cement, Antioxidant mix group; e: pre-treatment lower right first permanent Molar; f: Gaining access and cavity preparation; g: placement of Antioxidant mix; and h: Glass Ionomer cement.

\section{Sample size:}

Pulpotomy were performed in 54 vital decayed young permanent molars that indicated for vital pulp therapy. Children were divided into 3 equal groups

Group A: molars receiving Simvastatin after pulpotomy $(\mathrm{n}=18)$

Group B: molars receiving Antioxidant mix after pulpotomy $(\mathrm{n}=18)$

Group C: molars receiving calcium hydroxide after pulpotomy $(\mathrm{n}=18)$

\section{RESULTS}

According to pain, mobility and swelling; in simvastatin group immediately treatment of 18 $(100.0 \%)$ of cases were successful, at 1 month, 15 $(83.3 \%)$ of cases were successful and $3(16.7 \%)$ of cases was failure, and at 3 months, $15(83.3 \%)$ of cases were successful and $3(16.7 \%)$ of cases failed. Antioxidant mix group, immediately treatment of $18(100.0 \%)$ of cases were successful, at 1 month, $16(88.9 \%)$ of cases were successful and $2(11.1 \%)$ of cases failed, and at 3 months, $16(88.9 \%)$ of cases were successful and $2(11.1 \%)$ of cases failed.
Calcium hydroxide group, immediately treatment of $18(100.0 \%)$ of cases were successful, at 1 month, $16(88.9 \%)$ of cases were successful and $2(11.1 \%)$ of cases failed, and at 3 month, $16(88.9 \%)$ of cases were successful and $2(11.1 \%)$ of cases failed, Table (1).

According to Internal or external resorption, widening of periodontal ligament and Periapical radiolucency: in simvastatin group immediately treatment of $18(100.0 \%)$ of cases were successful, at 1 month, $15(83.3 \%)$ of cases were successful and $3(16.7 \%)$ of cases failed, and at 3 months, 15 $(83.3 \%)$ of cases were successful and $3(16.7 \%)$ of cases failed. Antioxidant mix group, immediately treatment of $18(100.0 \%)$ of cases were successful, at 1 month, $16(88.9 \%)$ of cases were successful and $2(11.1 \%)$ of cases failed, and at 3 months, 16 $(88.9 \%)$ of cases were successful and $2(11.1 \%)$ of cases failed. Calcium hydroxide group, immediately treatment of $18(100.0 \%)$ of cases were successful, at 1 month, $16(88.9 \%)$ of cases were successful and $2(11.1 \%)$ of cases failed, and at 3 months, 16 $(88.9 \%)$ of cases were successful and $2(11.1 \%)$ of cases failed Table (2) and Figure (2). 
TABLE (1): Comparison between the three studied groups according to I Pain, Mobility and Swelling.

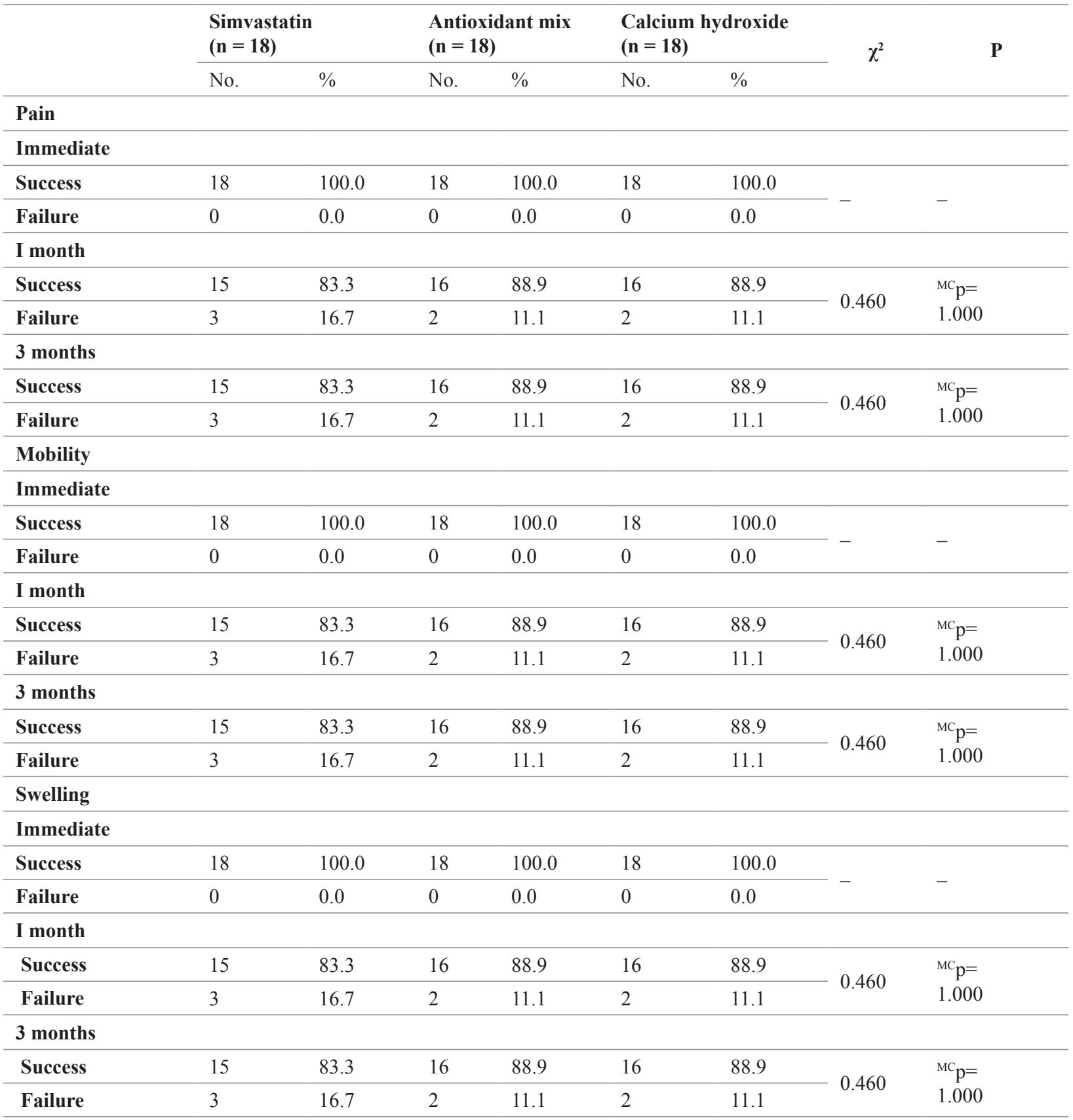

$p: p$ value for comparing between the two studied groups

*: Statistically significant at $p \leq 0.05$ 
TABLE (2): Comparison between the three studied groups according to Internal or external resorption, widening of periodontal ligament and Periapical radiolucency in each period.

\begin{tabular}{|c|c|c|c|c|c|c|c|c|}
\hline & \multicolumn{2}{|c|}{$\begin{array}{l}\text { Simvastatin } \\
(n=18)\end{array}$} & \multicolumn{2}{|c|}{$\begin{array}{l}\text { Antioxidant mix } \\
(\mathrm{n}=18)\end{array}$} & \multicolumn{2}{|c|}{$\begin{array}{l}\text { Calcium hydroxide } \\
(\mathrm{n}=18)\end{array}$} & \multirow[t]{2}{*}{$\chi^{2}$} & \multirow[t]{2}{*}{$\mathbf{P}$} \\
\hline & No. & $\%$ & No. & $\%$ & No. & $\%$ & & \\
\hline \multicolumn{9}{|c|}{ Internal or external resorption } \\
\hline \multicolumn{9}{|c|}{ Immediate } \\
\hline Success & 18 & 100.0 & 18 & 100.0 & 18 & 100.0 & \multirow{2}{*}{-} & \multirow{2}{*}{-} \\
\hline Failure & 0 & 0.0 & 0 & 0.0 & 0 & 0.0 & & \\
\hline \multicolumn{9}{|l|}{ I month } \\
\hline Success & 15 & 83.3 & 16 & 88.9 & 16 & 88.9 & \multirow{2}{*}{0.460} & \multirow{2}{*}{$\begin{array}{l}{ }^{\mathrm{MC}} \mathrm{p}= \\
1.000\end{array}$} \\
\hline Failure & 3 & 16.7 & 2 & 11.1 & 2 & 11.1 & & \\
\hline \multicolumn{9}{|l|}{3 months } \\
\hline Success & 15 & 83.3 & 16 & 88.9 & 16 & 88.9 & \multirow{2}{*}{0.460} & \multirow{2}{*}{$\begin{array}{l}{ }^{\mathrm{MC}} \mathrm{p}= \\
1.000\end{array}$} \\
\hline Failure & 3 & 16.7 & 2 & 11.1 & 2 & 11.1 & & \\
\hline \multicolumn{9}{|c|}{ Widening of periodontal ligament } \\
\hline \multicolumn{9}{|c|}{ Immediate } \\
\hline Success & 18 & 100.0 & 18 & 100.0 & 18 & 100.0 & \multirow{2}{*}{-} & \multirow{2}{*}{-} \\
\hline Failure & 0 & 0.0 & 0 & 0.0 & 0 & 0.0 & & \\
\hline \multicolumn{9}{|l|}{ I month } \\
\hline Success & 15 & 83.3 & 16 & 88.9 & 16 & 88.9 & \multirow{2}{*}{0.460} & \multirow{2}{*}{$\begin{array}{l}{ }^{\mathrm{MC}} \mathrm{p}= \\
1.000\end{array}$} \\
\hline Failure & 3 & 16.7 & 2 & 11.1 & 2 & 11.1 & & \\
\hline \multicolumn{9}{|l|}{3 months } \\
\hline Success & 15 & 83.3 & 16 & 88.9 & 16 & 88.9 & \multirow{2}{*}{0.460} & \multirow{2}{*}{$\begin{array}{l}{ }^{\mathrm{MC}} \mathrm{p}= \\
1.000\end{array}$} \\
\hline Failure & 3 & 16.7 & 2 & 11.1 & 2 & 11.1 & & \\
\hline \multicolumn{9}{|c|}{ Periapical radiolucency } \\
\hline \multicolumn{9}{|c|}{ Immediate } \\
\hline Success & 18 & 100.0 & 18 & 100.0 & 18 & 100.0 & \multirow{2}{*}{-} & \multirow{2}{*}{-} \\
\hline Failure & 0 & 0.0 & 0 & 0.0 & 0 & 0.0 & & \\
\hline I month & & & & & & & & \\
\hline Success & 15 & 83.3 & 16 & 88.9 & 16 & 88.9 & 0460 & ${ }^{\mathrm{MC}} \mathrm{p}=$ \\
\hline Failure & 3 & 16.7 & 2 & 11.1 & 2 & 11.1 & 0.460 & 1.000 \\
\hline 3 months & & & & & & & & \\
\hline Success & 15 & 83.3 & 16 & 88.9 & 16 & 88.9 & 0460 & ${ }^{\mathrm{MC}} \mathrm{p}=$ \\
\hline Failure & 3 & 16.7 & 2 & 11.1 & 2 & 11.1 & 0.460 & 1.000 \\
\hline
\end{tabular}

$p: p$ value for comparing between the two studied groups

*: Statistically significant at $p \leq 0.05$ 


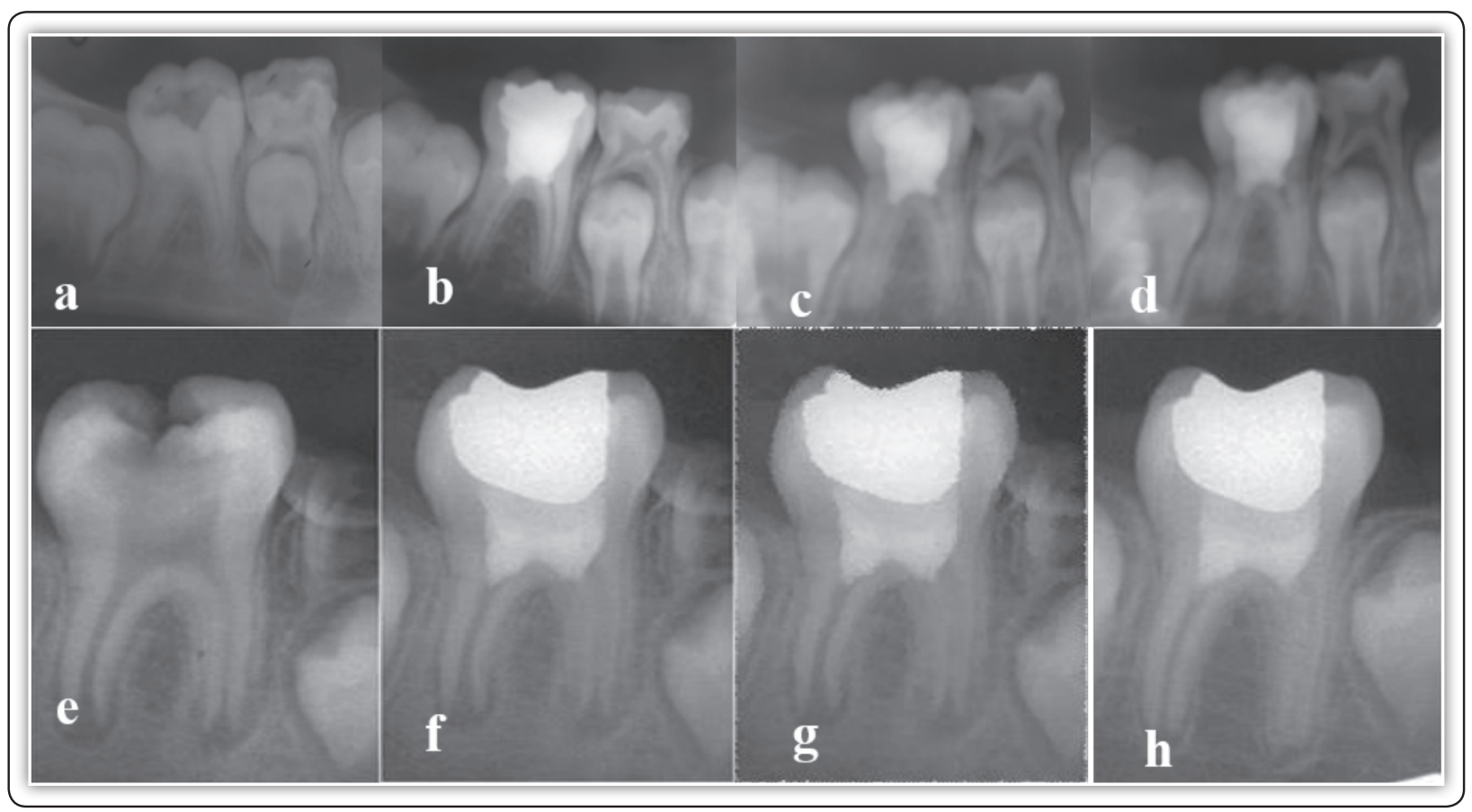

FIG (2) Simvastatin group: a: pre-treatment, b: immediate post-operative, c: after 1 month, d: after 3 months; Antioxidant mix group: e: pre-treatment, f: immediate post-operative, g: after 1 month, and h: after 3 months.

\section{DISCUSSION}

The present study was directed to evaluate, clinically and radiographically, the effect of Simvastatin and Antioxidant mix and Calcium Hydroxide on pulpotomized young permanent teeth. According to pain, mobility and swelling, the simvastatin group had a success rest of $83.3 \%$. Both the Antioxidant mix group and calcium hydroxide group had a higher success rate of $88.9 \%$ of cases.

According to internal or external resorption, widening of periodontal ligament and periapical radiolucency, the simvastatin group had the same success rate of $83.3 \%$, while both the Antioxidant mix and calcium hydroxide group had the higher success rate of $88.9 \%$.

Pain was reported in 3 cases. In two of them pain was associated with swelling and increased mobility (grade II) and recorded as treatment failure cases. For this reason, Apexification and/or endodontic treatment were performed for them.
Calcium hydroxide induce formation of a solid apical barrier. Some of the postulated mechanisms of the osteoconductive effects of $\mathrm{Ca}(\mathrm{OH})_{2}$ are, presence of high calcium concentration increase the activity of calcium dependent pyrophosphatease; direct effect on the apical and periapical soft tissue; High $\mathrm{pH}$ which may activate alkaline phosphatase activity and antibacterial activity ${ }^{(14)}$.

For decades calcium hydroxide has been the material of choice for use in vital pulp therapies and still it is the most frequently used one ${ }^{(15,16)}$. El Meligy et al., ${ }^{(17)}$ reported a success rate of $86.7 \%$ when calcium hydroxide was used as sealing material in pulpotomy of immature permanent teeth. Calcium hydroxide was selected as the control pulpotomy agent because it is currently considered the standard therapeutic agent for apexogenesis procedures in immature permanent teeth. Calcium hydroxide has a long and proven record as an effective pulp therapy agent, including pulpotomies, and it is not expensive. On the other hand, calcium hydroxide 
has high solubility and low strength. Surprisingly, recent trials revealed that calcium hydroxide pulpotomy had significantly greater pain-relieving effect initially, as well as higher radiographic success rates after 6-month follow-up ${ }^{(18)}$.

However, some studies show that there were shortcomings when using this material, such as superficial necrosis when placed in contact with vital pulp due to its high alkalinity $(\mathrm{pH}=12)$ and caustic effect, degradation over time and poor setting and sealing ability. Moreover, a dentinal bridge formed beneath the calcium hydroxide layer has tunnel defects which act as pathways for bacterial leakage and inflammatory changes of the pulp ${ }^{(19,20)}$.

Reddy et al. ${ }^{(10)}$, evaluated antioxidant mix, clinically and radiographically and found that only one tooth of 36 pulpotomized teeth failed. Possible explanation for the success rate observed in this study may be because antioxidant mix counter the excess proteases and free radicals often formed by neutrophil accumulation in the wounded area and protect protease inhibitors from oxidative damage. Fibroblasts and other cells may be killed by excess ROS and tissues will be made less flexible, so antioxidant substances will reduce the possibility of these adverse events occurring. Elimination of ROS may be an important strategy in improving healing of the radicular pulp.

Antioxidant activity is essential in protective stimulation osteoblastic activity through specific receptors ${ }^{(21)}$. Research that studied SEM samples showed mixed hard tissue barriers followed by characteristic tubular dentin barrier and complete hard tissue barrier formation after 9 months. SEM analysis of samples showing convex shaped hard tissue barrier formation may be proof of role of antioxidant material in localization and direction and morphology of the hard tissue barrier. These characters could have played an important role in clinical, radiographic, and histologic success. Several studies on antioxidants were found to improve healing ability ${ }^{(22,23)}$. Success in the present study shows that antioxidants are capable in radicular tissue repair and regeneration.

Antioxidant mix is newer pulpotomy medicament which works on the principle of wound healing and maintains anatomically continuity of damaged tissue ${ }^{(10)}$. Healing involves the activity of an intricate network of blood cell, growth factors, and cytokines which ultimately leads to the restoration to a normal condition of the injured radicular tissue. Antioxidants encounter excess of proteases and free radicals which are often formed by neutrophils accumulation in the wounded area and protect protease inhibitors from oxidative damage ${ }^{(24)}$.

Jeba et al. ${ }^{(25)}$, established a high success rate of pulpotomy clinically and radiographically with antioxidant mix (95\%) especially considering the long-term follow-up period. In 6 months follow up 1 failure was recorded and in 12 months follow up 2 failures were recorded. All molars treated with antioxidant mix presented a successful outcome.

Calcium hydroxide and Antioxidant mix pulpotomy are more cost-effective, easy in handling, biocompatible and does not have any disadvantage than any other commercially available medicament. It has been proven potentially to be an ideal pulpotomy agent clinical and radiographic. Hence, understanding the characteristics, tissue uptake metabolism, biochemical interactions, and the other biological activities of various antioxidants on pulpal healing may provide a reliable biological method for vital pulp therapy of primary teeth and young permanent teeth in the clinical practice.

\section{CONCLUSIONS}

From the results of the present study, the following conclusions could be drawn:

1. Simvastatin and Antioxidant mix pulpotomy are cost effective, with ease in handling, and biocompatible. It has been proven potentially to be an ideal pulpotomy agent clinical and radiographic result as a pulp medicament material in treatment of vital young permanent teeth. 
2. All three tested materials enhanced root formation "elongation" without significant difference, without any change in periodontal tissue.

\section{REFERENCES}

1. Bhayat A, Ahmad M, Hifnawy T, Mahrous M, Al-Shorman $\mathrm{H}$. Correlating dental caries with oral bacteria and the buffering capacity of saliva in children in Madinah, Saudi Arabia. J IntSocPrev Community Dent 2013;3:38-43.

2. Yang F, Zhang Y, Yuan X, Yu J, Chen S. Caries experience and its association with weight status among 8-yearold children in Qingdao, China. J IntSocPrev Community Dent 2015; 5: 52-8.

3. Witherspoon D. Vital pulp therapy with new materials: new directions and treatment perspectives-permanent teeth. J Endod 2008; 34:S25-8.

4. Avram D, Pulver F. Pulpotomy medicaments for vital primary teeth: surveys to determine use and attitudes in pediatric dental practice and in dental schools throughout the world. ASDC J Dent Child 1989; 56: 426-34.

5. Fuks A, Eidelman E, Cleaton-Jones P, Michaeli Y. Pulp response to ferric sulfate, diluted formocresol and IRM in pulpotomized primary baboon teeth. ASDC J Dent Child 1997; 64: 254-9.

6. Mayes P, Botham K, Marray R, Granner D.chlosterol synthesis, transport and excretion. Mc Grow Hill; 2003:21930 .

7. Okamoto Y, Sonoyama W, Ono M, Akiyama K, Fujisawa T. Simvastatin Induces the odontogenic differentiation of human dental pulp stem cells In Vitro and In Vivo. J Endod 2009; 35:367-72.

8. Seto H, Ohba H, Tokunaga K, Hama H, Horibe M, Nagata T. Topical application of simvastatin recovers alveolar bone loss in rats. J Periodontal Res 2008;43:261-7.

9. Min K, Lee Y, Hong S, Kim E. Simvastatin promotes odontoblastic differentiation and expression of angiogenic factors via heme oxygenase- 1 in primary cultured human dental pulp cells. J Endod 2010; 36:447-52.

10. Reddy M, Niharika P, Reddy H, Reddy N, Kumar M. Antioxidant mix: A novel pulpotomy medicament: A scanning electron microscopy evaluation. Contemp Clin Dent 2014; 5:428-33.

11. Aksakalli S. Antioxidants in dentistry: Review of literature. Dentistry 2013; 4:1-3.
12. Girish M, Prakash L. Clinical and radiographic evaluation of mineral trioxide aggregate and electrosurgical pulpotomies in primary molars: An in vivo study. J Int Oral Health 2016; 8:601-6.

13. Aminabadi N, Maljaei E, Erfanparast L, Aghbali A. Simvastatin versus calcium hydroxide direct pulp capping of human primary molars: A randomized clinical trial. J Dent Res Dent Clin Dent Prospect 2012;7:1:8-14.

14. Mary R, Apexification : a review. Endodontic Dental Traumatology $2005: 21$ (1) : 1

15. Nosrat, A, and Saeed A. "Apexogenesis treatment with new endodontic cement: A case report." Journal of Endodontics, Vol. 36, No. 5, 2010, pp. 912-14.

16. 16.Witherspoon, David E. "Vital pulp therapy with new materials: new directions and treatment perspectives permanent teeth." Pediatric Dentistry, Vol. 30, No. 3, 2008, pp. 220-24.

17. El Meligy, Omar AS, and David R. Avery. "Comparison of mineral trioxide aggregate and calcium hydroxide as pulpotomy agents in young permanent teeth (apexogenesis)." Pediatric Dentistry, Vol. 28, No. 5, 2006, pp. 399-404.

18. Asgary, S., and M. J. Eghbal. "A clinical trial of pulpotomy vs. root canal therapy of mature molars." Journal of Dental Research, Vol. 89, No. 10, 2010, pp. 1080-85.

19. Barrieshi-Nusair, Kefah Mahmood, and Muawia Abdulla Qudeimat. "A prospective clinical study of mineral trioxide aggregate for partial pulpotomy in cariously exposed permanent teeth." Journal of Endodontics, Vol. 32, No. 8, 2006, pp. 731-35.

20. Bortoluzzi, Eduardo Antunes, et al. "Mineral trioxide aggregate with or without calcium chloride in pulpotomy." Journal of Endodontics, Vol. 34, No. 2, 2008, pp. 172-75.

21. Banfi, Iorio E, Corsi M. Oxidative stress, free radicals and bone remodeling. Clin Chem Lab Med 2008;46:1550-5.

22. Porto da Rocha R, Lucio D, Souza T, Pereira S, Fernandes G. Effects of a vitamin pool (Vitamins A, E, and C) on the tissue necrosis process: Experimental study on rats. Aesthetic Plast Surg 2002;26:197-202.

23. Rasik A, Shukla A. Antioxidant status in delayed healing type of wounds. Int J Exp Pathol 2000;81:257-63.

24. Aksakalli S. Antioxidants in dentistry: Review of literature. Dentistry 2013;4:1-3.

25. Jeba E, Saravanan T, Balasubramanian B. Natural antioxidants in dentistry - Review article. International Journal of Dental Sciences and Research 2015;3:20-3. 